\title{
Urbanisation and its effect on risk factors associated with childhood diarrhoea in Mbour, Senegal: A visualisation
}

\author{
Sokhna Thiam,,${ }^{1,2}$ Samuel Fuhrimann, ${ }^{1-3}$ Aminata Niang-Diène, ${ }^{4}$ Ibrahima $\mathrm{Sy},{ }^{4,5}$ \\ Ousmane Faye, ${ }^{6}$ Jürg Utzinger, ${ }^{1,2}$ Guéladio Cissé ${ }^{1,2}$ \\ ${ }^{1}$ Swiss Tropical and Public Health Institute, Basel; ${ }^{2}$ University of Basel, Basel, Switzerland; ${ }^{3}$ School of \\ Public Health and Family Medicine, University of Cape Town, Cape Town, South Africa; ${ }^{4}$ Department of \\ Geography, Université Cheikh Anta Diop de Dakar, Dakar; ${ }^{5}$ Centre de Suivi Ecologique, Dakar; \\ ${ }^{6}$ Department of Animal Biology, Université Cheikh Anta Diop de Dakar, Dakar, Senegal
}

\begin{abstract}
Rapid urbanisation, particularly in secondary cities in Africa, brings along specific challenges for global health, including the prevention and control of infectious diseases such as diarrhoea. Our purpose was to visualise urbanisation trends and its effect on risk factors associated with childhood diarrhoea, e.g. water supply, sanitation, wastewater and solid waste management in Mbour, a
\end{abstract}

Correspondence: Guéladio Cissé, Swiss Tropical and Public Health Institute, P.O. Box, CH-4002 Basel, Switzerland.

Tel: +41-61-284-8304 - Fax: +41-61-284-8105.

E-mail: gueladio.cisse@swisstph.ch

Key words: Visualisation; Urbanisation; Childhood; Diarrhoea; Senegal.

Acknowledgements: we are grateful to the local services for their support in the data collection, specifically the National Agency of Statistic and Demography, the Service Départemental d'Urbanisme et de l'Habitat, the Service Départemental du Cadastre, the National Office of Sanitation, and the Municipality of Mbour. Our special thanks go to the community members for their kind collaboration and participation in the study, as well as the field team in Senegal for their collaboration and commitment during the survey. We are grateful to Ms. Amena Briët for her voice-over in the accompanying video. The study received financial support from the Swiss Government Excellence Scholarships for Foreign Scholars (ESKAS scholarship) and Böniger-Ris Foundation at the University of Basel.

Video link: https://www.youtube.com/watch?v=DRQJgu2WiXg\&t=5s

Received for publication: 12 October 2017.

Accepted for publication: 16 November 2017.

CC Copyright S. Thiam et al., 2017

Licensee PAGEPress, Italy

Geospatial Health 2017; 12:632

doi:10.4081/gh.2017.632

This article is distributed under the terms of the Creative Commons Attribution Noncommercial License (CC BY-NC 4.0) which permits any noncommercial use, distribution, and reproduction in any medium, provided the original author(s) and source are credited. secondary city in south-western Senegal. Our visualisation is facilitated by epidemiological and geographical surveys carried out in 2016. A deeper spatial and visual understanding of the urbanisation trends and the disparities of diarrhoea-associated risk factors might lead to the implementation of suitable health interventions and preventive measures. Our visualisation is aimed to serve as a basis for discussion and as a decision support tool for policymakers, municipal officials and local communities to prioritise interventions related to water, sanitation and waste management with a view to reduce the environmental and health risks in the rapidly growing city of Mbour, which is set as an example for other similar secondary cities across low- and middle-income countries in Africa.

\section{Introduction}

The world is becoming increasingly urban, a process that has accelerated since the industrial revolution that commenced in the late $18^{\text {th }}$ century (Neiderud, 2015). For instance, in 2016, 3.8 billion people were concentrated in urban settings, thus accounting for approximately $54 \%$ of the world's population (UN, 2015). A further increase in urban population growth is expected in the coming decades, particularly in Africa and Asia (UN, 2015). Africa's population might rise to 2.4 billion by 2050 and $56 \%$ of this population is expected to live in urban settings (UN, 2015). In West Africa, the second fastest growing part after East Africa on this continent, two-third of the population are expected to be urban dwellers by 2050 (UN-HABITAT, 2014).

An important feature of rapid, urban growth is the disproportionate expansion of secondary cities, which are also known as medium-sized cities, a term popularised by Rondinelli in the 1980s and now commonly used to describe the second level in the hierarchy of cities below the primary level (i.e. big city) (Rondinelli, 1983). The definition of a secondary city is contextual: it can relate to population size, function, urban hierarchy as well as its economic and social structure. Rondinelli's definition has secondary cities as urban settlements with a population of at least 100,000 that does not include the big cities in a country, while UN-HABITAT defines it as an urban area with a population of between 100,000 and 500,000 (UN-HABITAT, 1996; Rondinelli, 1983). Today, secondary cities range in population size from a few hundred thousand to several million. There are more than 4,000 cities in the world with a population exceeding 100,000 people and this number is expected to increase to 6,000 by 2050 (Angel, 2012). Nearly two-thirds of the world's sec- 
ondary cities are currently located in Africa and Asia (World Bank, 2009).

African cities pose particular challenges to global health not only due to the high rates of urbanisation, but also because of unplanned settlements. As a result, environmental risks and health disparities are widening, both in terms of infectious diseases (e.g. diarrhoeal diseases) and non-communicable diseases. Risks to human health are accentuated in the urban environment where population density is high and the likelihood of exposure to disease equally high (Satterthwaite and Bartlett, 2017). For many of the rapidly growing secondary African cities, the absence of basic services, such as access to safe drinking water and sanitation, affordable housing and waste management, is particularly severe for the poorest and most marginalised communities (UN-HABITAT, 2014). In 2015, it was estimated that 319 and 695 million people in sub-Saharan African still used below-standard sources of drinking water and unimproved sanitation, respectively (WHO/UNICEF, 2015). This is a particularly pressing problem where the urban informal settlements are growing faster than the ability of administrations to provide the basic services can cope. Lack of such services affects the health and wellbeing of people, mostly children under the age of 5 years leading to increased health risks and vulnerability. Resulting global health challenges include the control of infectious diseases such as diarrhoeal diseases (GBD 2015 DALYs and HALE Collaborators, 2016).

According to the World Health Organization (WHO, 2017), infectious diseases are still a major public health problem in African cities. The three main causes of death in these settings are infectious diseases, namely lower respiratory infections, diarrhoeal diseases and tuberculosis (TB) (WHO). Diarrhoea is one of the infectious diseases most responsive to environmental and sociosanitary risk factors. Globally, diarrhoea caused 1.4 million deaths in 2015, and children under the age of 5 years are the most affected age group with one in 10 childhood deaths due to diarrhoea (WHO, 2017). Nearly half of this diarrhoeal burden occurs in Africa and Asia, classified at the same time as the most rapidly urbanising settings (WHO, 2017).

In Senegal, a country where secondary cities struggle to provide basic services, diarrhoea is the leading cause of death among children under the age of 5 years, responsible for $14 \%$ of total disability-adjusted life years (DALYs) in this age group (GBD 2015 Child Mortality Collaborators, 2016; GBD 2015 DALYs and HALE Collaborators, 2016). Of note, Senegal's urban population has doubled in the past 60 years; it was $23 \%$ in $1960,45 \%$ in 2013 and is projected to reach $60 \%$ by 2030 (World Bank, 2016). In the Senegalese context, urban is defined as a city of 10,000 people or more.

Although prior research has investigated the interactions between urbanisation, environment and health, little is known regarding urbanisation and its health effects in secondary cities since most of this research was conducted in big cities. Hence, the aim of the present study was to expand our understanding of urbanisation trends and its effect on risk factors for diarrhoea in the secondary coastal city of Mbour in south-western Senegal. The following questions guided our vHealth contribution: i) what are typical urbanisation trends and how does urbanisation affect risk factors for childhood diarrhoea? ii) Are risk factors for diarrhoea among children below the age of 5 years in Mbour spatially clustered? iii) What are the priority interventions that can reduce the burden of childhood diarrhoea and which are the high-risk areas?

Our study was carried out in the Senegalese city of Mbour located near the Atlantic Ocean in the region of Thiès (Figure 1). We employed a multidisciplinary approach, including a literature review, a cross-sectional epidemiological household survey, microbial water sampling and a geographical survey facilitated by global positioning system (GPS) data collection to locate the major environmental risk factors and a questionnaire interview with urban planners on the spatial expansion of the city. We carried out a cross-sectional epidemiological survey with spatial random sampling between September and October 2016. A total of 800 households were sampled and distributed in the four zones, which represent the socio-spatial heterogeneity of the city: Urban Central Areas (UCA), Peri-Central Areas (PCA), Northern Peripheral Areas (NPA) and Southern Peripheral Areas (SPA). Households were randomly selected within the aforementioned zones. A twostage procedure was used to identify households with children under the age of 5 years. We allocated the targeted sample to each zone in proportion to its population and allocated the targeted sample of each zone in the entire neighbourhood, which allowed covering the whole city in order to better analyse the disparities. The survey comprised two components: i) a tablet-based questionnaire yielding information on water, sanitation and hygiene (WASH) and diarrhoea occurrence among children; and ii) collection of water samples to determine microbial contamination of stored drinking water at home. A membrane filtration method was used to detect Escherichia coli and faecal coliform bacteria in households that stored drinking water. For the geographical survey, a Garmin GPS device (eTrex ${ }^{\circledR} 30$; Garmin Ltd, Olathe, KS, USA) was used to locate environmental factors at the community level, such as wells, stagnant wastewater points, solid-waste dumping, potential flood areas and stagnant rainwater points. Applied software packages were: Microsoft Power Point 2010 (Microsoft Corporation; Edmond, WA, USA) for content visualisation including geospatial components; ArcGIS version 10.2.1 (ArcMap; ESRI; Redlands, CA, USA) for map production; Camtasia Studio version 9 (TechSmith Corporation; Okemos, MI, USA) for production of video for Internet streaming (Goolge Earth Pro, version 7.1.2.2041; Google Inc.; Mountain View, CA, USA).

The demographic and spatial data showed an exponential population growth followed by a rapid spatial expansion of the city from 1922 to date resulting in the creation of neighbourhoods with poor environmental conditions with regard to safe water and sanitation. Since its creation in 1926 as a colonial trading port by colonialists, the population of Mbour has grown rapidly and steadily increasing from 1,700 in 1926 to 18,600 in 1966 and from 170,436 inhabitant in 2002 to 232,777 inhabitants in 2013 (ANSD, 2014). This rapid growth resulted in an important spatial expansion, which increased the city surface from 175 ha in 1945 to 894 ha in 1976 and on to more than 1,300 ha in 2012. This expansion had considerable consequences with respect to urban planning. The city is facing a deficit of urban infrastructure and poor service delivery, such as affordable housing, access to safe drinking water and improved sanitation, as well as domestic wastewater and solidwaste management. An important unequal distribution of urban basic services in space and time was observed. Differences concerning the access to drinking water were observed, with very low rates of connection in the new neighbourhoods with an inexistent rate of connection in Baye Deuk, and variable rates in other neighbourhoods located in the peri-central area.

The findings from the cross-sectional household survey showed an insufficiency in clean water access, hygiene and sanitary systems in Mbour that foster diarrhoea transmission pathways. 
It showed that only $58.6 \%$ of the surveyed household were connected to water networks with significant disparities between zones and neighbourhoods. Less than half $(40.5 \%)$ were connected to the water network in NPA with only $17.8 \%$ in Medine and $21.7 \%$ in Liberte. In SPA only $12.0 \%$ were connected to the network with zero percent in Gouye Mouride, $7.5 \%$ in Oncad and $14.3 \%$ in Zone Sonatel. Our study revealed a persistence of traditional modes of water supply in the peripheral neighbourhoods and showed a high use of wells in NPA and SPA with $77.9 \%$ of the visited household in Medine, $71.4 \%$ in Zone Sonatel and $33.9 \%$ in Grand Mbour. The wells are used in spite of being untreated and polluted since the water network does not reach these neighbourhoods. The city has no functional sewerage system and dwellers are mainly using on-site sanitation facilities. The topography is relatively flat and the proximity to the sea puts the city at risk of seasonal urban floods. The findings also revealed that $72 \%$ of the study population empty their wastewater in the street, which might contaminate drinking water source and increase the diarrhoea risk among children, a practice common all over the city with more than $80 \%$ in some neighbourhoods.

Our study showed that $44.5 \%$ of the visited household had at least one child with diarrhoea in the two weeks prior to the interview. The two-week point prevalence rate was $33.9 \%$ with a significant difference between zones. The highest prevalence was found among children living in UCA (38.3\%), followed by those living in SPA (37.2\%) and the lowest prevalence was observed in NPA with $26.9 \%$. We also looked at the prevalence by neighbourhood and found that in UCA, the highest prevalence was observed in the following neighbourhoods: Tefess (57.1\%), Zone Residentielle (54.3\%); in PCA, diarrhoea prevalence was highest in Baye Deuk (57.9\%); in SPA the prevalence was higher in Zone Sonatel $(46.1 \%)$. Descriptive and analytical mapping revealed that the spatial distribution of diarrhoeal diseases prevalence was governed by specific environmental and socio-sanitary risk factors. Environmental factors such as unimproved water sources, sanitation, wastewater and solid waste management, and bacteriological aspects (e.g. water contamination with E. coli and other faecal coliform bacteria, which indicate faecal contamination) are the main drivers explaining the spatial distribution of diarrhoea in the city. Diarrhoeal prevalence was higher in the neighbourhoods with the largest number of contaminated water especially in the most densely populated neighbourhoods of the city (e.g. Tefess, Golf and

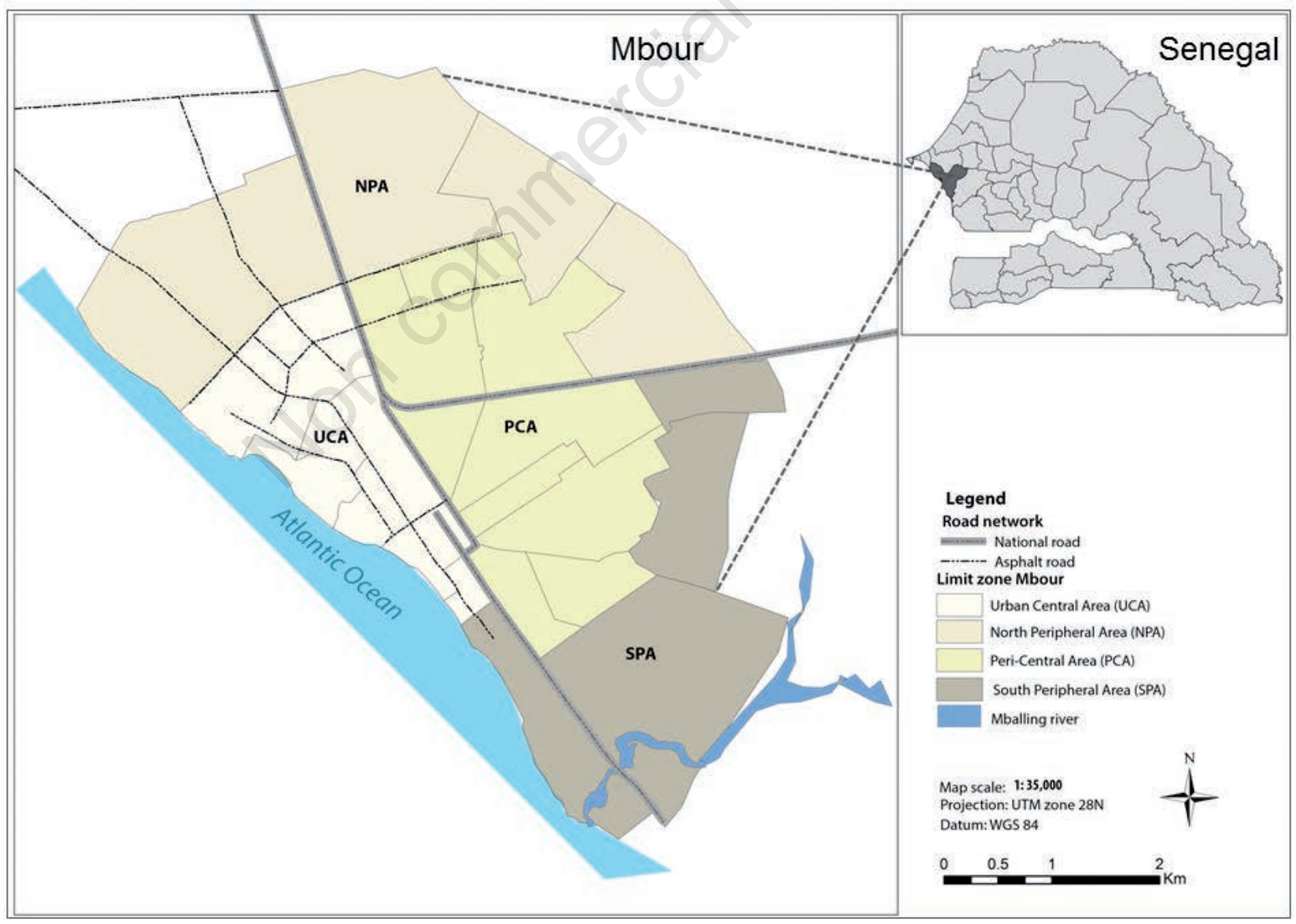

Figure 1. Map showing Mbour in Senegal stratified in the four different research zones (based on Thiam et al., 2017: Prevalence of diarrhoea and risk factors among children under five years old in Mbour, Senegal: a cross-sectional study. Infect Dis Poverty 6:109). 
Baye Deuk). Our data show that there is considerable spatial heterogeneity of vulnerability and risk for diarrhoeal transmission.

\section{Visualisation and outlook}

The purpose of our study was to visually characterise the trends of urbanisation and highlight disparities of environmental risk factors associated with diarrhoeal diseases in a secondary city of West Africa to help policymakers and city officials to better plan their action. Our visualisation is structured as follows. First, we provide a general overview of the urbanisation trends in Mbour by highlighting the demographic growth and the spatial expansion of the city boundaries over the past 60 years. Second, we highlight risk factors for childhood diarrhoea. These include the urban infrastructures related to drinking water and sanitation coverage, wastewater and solid waste management. Third, we show how our work can help urban planners, public-health experts and other relevant stakeholders to better prioritise interventions and preventive measures in order to reduce the burden of diarrhoea in Mbour.

\section{Conclusions}

Our visualisation emphasises important heterogeneity in terms of access to clean water, improved sanitation and hygiene and its effect on childhood diarrhoea. We believe that our contribution in the series of short video presentations put forth by the international journal Geospatial Health, which are readily accessible by policymakers, local communities and others stakeholders, further underscores the value and potential of this format (Fuhrimann et al., 2014; Krieger et al., 2012). Indeed, our visualisation can serve as a decision support tool to policymakers and municipal officials for implementation and policy development related to safe drinking water, sanitation infrastructures (including wastewater and solid waste management) and can support spatial and temporal targeted interventions designed to reduce risk factors in the population. It can also be used to geographically support accurate future implementation of preventive measures against diarrhoea in children below the age of 5 years through community education on the importance of WASH, household and community systems for treating and storing water, rotavirus vaccination, etc. in the rapidly growing secondary city of Mbour. Our methods and approaches might be applicable to others cities in West Africa and elsewhere.

\section{References}

Angel S, 2012. Planet of cities. Lincoln Institute of Land Policy, Cambridge, MA, USA.

ANSD, 2014. Recensement général de la population et de l'habitat, de l'agriculture et de l'elevage. République du Sénégal,
Ministère de l'Economie, des Finances et du Plan, Dakar, Senegal.

Fuhrimann S, Winkler MS, Schneeberger PHH, Niwagaba CB, Buwule J, Babu M, Medlicott K, Utzinger J, Cissé G, 2014. Health risk assessment along the wastewater and faecal sludge management and reuse chain of Kampala, Uganda: A visualization. Geospat Health 9:251-5.

GBD 2015 Child Mortality Collaborators, 2016. Global, regional, national, and selected subnational levels of stillbirths, neonatal, infant, and under-5 mortality, 1980-2015: A systematic analysis for the Global Burden of Disease study 2015. Lancet 388:1725-74.

GBD 2015 DALYs and HALE Collaborators, 2016. Global, regional, and national disability-adjusted life-years (DALYs) For 315 diseases and injuries and healthy life expectancy (HALE), 1990-2015: A systematic analysis for the global burden of disease study 2015. Lancet 388:1603-58.

Krieger GR, Bouchard MA, De Sa IM, Paris I, Balge Z, Williams D, Singer BH, Winkler MS, Utzinger J, 2012. Enhancing impact: visualization of an integrated impact assessment strategy. Geospat Health 6:303-6.

Neiderud CJ, 2015. How urbanization affects the epidemiology of emerging infectious diseases. Infect Ecol Epidemiol 5:27060.

Rondinelli DA, 1983. Secondary cities in developing countries: Policies for diffusing urbanization. SAGE Publications, Thousand Oaks, CA, USA.

Satterthwaite D, Bartlett S, 2017. Editorial: The full spectrum of risk in urban centres: changing perceptions, changing priorities. Environ Urban 29:3-14.

Thiam S, Diene AN, Fuhrimann S, Winkler MS, Sy I, Ndione JA, Schindler C, Vounatsou P, Utzinger J, Faye O, Cissé G, 2017. Prevalence of diarrhoea and risk factors among children under five years old in Mbour, Senegal: a cross-sectional study. Infect Dis Poverty 6:109.

UN-HABITAT, 1996. The management of secondary cities in Southeast Asia. United Centre for Human Settlements, Nairobi, Kenya.

UN-HABITAT, 2014. The state of African cities 2014: Re-imagining sustainable urban transitions. United Centre for Human Settlements, Nairobi, Kenya.

UN, 2015. World urbanization prospects: the 2014 revision. United Nations, Department of Economic and Social Affairs, Population Division, New York, NY, USA.

WHO, 2017. The top 10 causes of death. Available from: http://www.who.int/mediacentre/factsheets/fs310/en/

WHO/UNICEF, 2015. Progress on drinking water and sanitation: 2015 update and MDG assessment. UNICEF and World Health Organization, Geneva, Switzerland.

World Bank, 2009. Systems of cities: harnessing urbanization for growth and poverty alleviation. World Bank, Washington, DC, USA.

World Bank, 2016. Perspectives urbaines: villes émergentes pour un Sénégal émergent. World Bank, Washington, DC, USA. 